\title{
Casos controversos sob o enfoque de um paradigma indiciário: o ensino de ciências no horizonte formativo da cidadania ambiental
}

\author{
Carmen Roselaine de Oliveira Farias*
}

Elisabeth Barolli ${ }^{* *}$

\section{Resumo}

Neste artigo, será apresentada uma crítica aos modelos epistemológicos e pedagógicos dominantes no ensino de ciências e uma perspectiva sobre o uso de casos controversos que leva em conta expectativas de formação para a cidadania socioambiental. O argumento central é que casos podem contribuir para a compreensão de questóes ambientais na escola a partir de uma postura investigativa que tem suas raízes em um modelo epistemológico das ciências humanas, que pode ser designado por "paradigma indiciário". Para isso, busca-se problematizar nossas formas de produzir conhecimentos escolares nas áreas das ciências e oferecer uma fundamentação teórica e metodológica para o uso de casos controversos na educaçáo escolar, destacando suas contribuiçôes para a educação ambiental. Conclui-se o artigo sustentando que, para além de conhecer argumentos técnicos e científicos sobre controvérsias ambientais, uma metodologia de ensino fundamentada em casos controversos contribuiria para desvelar aquilo que não está absolutamente explícito nesses argumentos como: o caráter social e político da ciência e da tecnologia e a nossa implicação na história e no ambiente como sujeitos morais.

Palavras-chave: Ensino de ciências. Educação ambiental. Casos controversos.

\footnotetext{
* Doutora em Educação pela Universidade Federal de São Carlos (UFSCar). Professora do Departamento de Biologia da Universidade Federal Rural de Pernambuco (UFRPE).

** Doutora em Educação pela Universidade de São Paulo (USP). Professora da Faculdade de Educação da Universidade Estadual de Campinas (UNICAMP).
} 


\section{Introdução}

O uso educativo de casos controversos tem estado presente no campo da educação científica como um modo de romper com a tradicional fragmentação dos conteúdos escolares e com sua abordagem descontextualizada. Na perspectiva das relaçốes entre Ciência, Tecnologia e Sociedade (CTS), o uso de casos como estratégia didática procura superar o caráter abstrato comumente atribuído aos conhecimentos científicos, integrando a eles elementos que compóem o universo cultural e social (REIS, 2007; SILVA; CARVALHO, 2007; FARIAS; CARVALHO, 2006). Entre os objetivos dessas abordagens educativas está o de criar condiçôes para que as pessoas possam apreciar a complexidade das problemáticas contemporâneas, justamente aquelas que podem dar sentido ao esforço de aprendizagem e de engajar os alunos nos contextos e problemas sociais, tornando-os mais capazes para agir, interagir e se posicionar de forma esclarecida diante das questóes de nosso tempo. Como argumenta Cerezo (1999), cada vez mais se tem imposto a necessidade de estimular o estudo das ciências e da tecnologia para favorecer o desenvolvimento e a consolidação de atitudes e práticas democráticas em questôes de importância social, relacionadas com a inovação tecnológica e com a intervenção ambiental.

Apesar da crescente importância que esses objetivos têm assumido nos campos da educação científica, sua implementação na escola básica tem encontrado dificuldades de diversas naturezas. De fato, a realizaçáo das perspectivas CTS requer mudanças nas práticas escolares, que vão implicar no desenho de métodos e estratégias de ensino renovados e criativos que efetivamente contribuam para problematizar questôes de natureza ética e cultural, envolvidas na produção científica e tecnológica (SANTOS, 2005).

Os casos controversos, em particular, têm o potencial de criar condições para que o aprendiz se defronte com um leque maior de variáveis complexas e interdependentes. Tais casos, quando referentes a situaçóes reais, implicam em seu estudo diferentes áreas do conhecimento, assim como a compreensão de contextos culturais, sociais, políticos, científicos e tecnológicos que se interrelacionam. Essas características fazem dos casos estratégias interessantes para um aprendizado "significativo", envolvendo alunos e professores em situaçốes de investigaçâo inter e transdisciplinares, a partir das quais podem ser desenvolvidas competências diversas, espírito crítico, atitudes e valores relevantes do ponto de vista pessoal e social (CACHAPUZ, 2000; POZO; CRESPO, 2009). 
Neste artigo, destacamos elementos que fundamentam teórica e metodologicamente o uso educativo de casos controversos no ensino de ciências, considerando-se os requerimentos formativos da "cidadania ambiental". Segundo Santos (2005), a cidadania ambiental é uma recente dimensão da cidadania que decorre da crescente intensificação dos problemas ambientais agravados pela sinergia com os problemas sociais. As causas, as consequências e as necessárias respostas aos fatos evidenciados por esta problemática, legitimam os direitos ambientais em termos éticos e legais, conferindo reconhecimento social a esta nova dimensão da cidadania. É interessante sublinhar que, na visão da autora, a cidadania passou a ter uma dimensão ambiental quando a ciência e a tecnologia passaram a estar na origem de muitos dos nossos problemas contemporâneos. Podemos mesmo dizer que com isso a cidadania passou a ter um sentido multidimensional e integrador:

[a cidadania ambiental] articula direitos humanos, economia, ecologia, conhecimento e política, numa visão integrada. Repensa a soberania política, o estilo de vida a que nos habituamos, o sistema de valores que nos rege, os direitos humanos, a ciência, a tecnologia, o mercado e as articulaçóes CTS, no sentido de um novo contrato social (SANTOS, 2005, p. 81).

As demandas contemporâneas da cidadania também rebatem na educação. Dessa última, espera-se que não apenas difunda as prerrogativas do cidadão, como também venha a atuar na promoção da cidadania por meio de atos educativos democráticos, participativos, ativos, conscientes, intencionais e sistemáticos, tendo no horizonte uma "formação cidadā" que cultive o pensamento crítico e a identidade pessoal, social, espacial, temporal, cultural e ecológica do cidadão, indispensáveis como resposta às constantes mudanças e controvérsias socioambientais e sociocientíficas do século XXI (SANTOS, 2005).

Abordar na educação científica situaçôes sobre as quais não existe um consenso social que lhes confira estabilidade de julgamento científico e ético constitui-se numa possibilidade de formaçáo da cidadania. Na perspectiva deste trabalho, em particular, isso se justifica em grande parte pelo fato de que o enfrentamento de tais situaçóes-problema pode permitir o exercício de uma postura investigativa que tem suas raízes num modelo epistemológico das 
ciências humanas, em acordo ao que Ginzburg (1989) denomina "paradigma indiciário". Essa postura nos parece essencial não só porque se propõe a conjecturar sobre as múltiplas dimensões das questóes controversas com as quais nos defrontamos hoje, mas, sobretudo, porque pode contribuir para que os sujeitos se impliquem nessas questóes no sentido da construção de uma nova ética.

Queremos, com isso, problematizar o ensino de ciências tomando por base a questáo ambiental, tendo em vista que essa questáo ilustra de maneira eloquente a natureza das controvérsias atuais na nossa sociedade e ajuda-nos a desenvolver uma fundamentação epistemológica e metodológica para uma abordagem da educação científica que integre os legados históricos dos movimentos de Ciência, Tecnologia, Sociedade e Ambiente (CTSA), e da educação ambiental (MAYER, 1998; AIKENHEAD, 2000; PAYNE, 2000; AMORIM, 2001; AULER; BAZZO, 2001; LAYRARGUES, 2004; GAUDIANO, 2005; SAUVÉ, 2005; FARIAS; FREITAS, 2007; GRÜN, 2007; LOUREIRO; LIMA, 2009; CARVALHO, 2010; COSENZA; MARTINS, 2011; GUIMARÁES, 2011).

\section{O problema: os modelos epistemológicos e pedagógicos em questão}

Apesar de hoje ser frequente ouvirmos falar em enfoque sistêmico, holístico, multi, inter e transdisciplinar, especialmente no campo da educaçáo escolar e dos estudos ambientais, não podemos ignorar o fato de que abordagens dessas naturezas nâo são triviais de serem alcançadas. O que se observa com frequência nesses campos é o esforço em compreender uma situação complexa, suas causas e origens, atribuindo-lhe uma soluçáo e, desse modo, afrontando-se os efeitos secundários da sociedade industrial.

La escuela tiende a trasmitir no los problemas sino las soluciones - las leyes "naturales", las fórmulas para calcular, la "correcta" interpretación histórica, los significados "apropiados" de los textos literarios. La escuela "trasmisiva" necesita certezas que justifiquen su papel; el saber debe ser cierto, universal, objetivo. Pero incluso la escuela "constructiva", que actualmente representa la alternativa más avanzada, por un lado, 
declara que los estudiantes deben construir el propio saber, pero no se ofrece a sí misma como ejemplo de construcción crítica del saber, de un enfoque plural de las disciplinas. En este sentido, su objetivo parece ser el de reconstruir las mismas certezas (de la escuela de antes), y difícilmente acepta que se construyan saberes, y epistemologías, diversos a los codificados. (MAYER, 1998, p. 222) ${ }^{1}$.

A problemática socioambiental é, sem dúvida, ilustrativa de situaçóes que se constituem num verdadeiro desafio para o modelo - ou paradigma - epistemológico da ciência moderna, sobretudo pelo fato de que essa problemática não pode ser idealizada, o que na produção do conhecimento das Ciências Físicas, por exemplo, constitui-se num procedimento comum. Ao contrário, a análise e a compreensão dessas problemáticas requerem, justamente, que seja considerada a complexa rede de inter-relaçóes dos fenômenos naturais, bem como dos contextos sociais e políticos. Atender a essa perspectiva implica, a nosso ver, problematizar epistemologias sobre as quais as práticas escolares têm se apoiado, mas que muitas vezes - sobretudo no caso das problemáticas socioambientais - não têm dado conta de ultrapassar uma cultura da simplificação e do reducionismo em direção a uma "cultura da complexidade".

Parece-nos que o problema de fato surge no momento em que se confunde o conhecimento com a realidade, a ciência com os fenômenos, e se pretende, por meio disso, açambarcar algum tipo de conhecimento supostamente "seguro" e "total" sobre o mundo. Contudo, isso não significa, simplesmente, rejeitar a ciência e a tecnologia modernas. $\mathrm{O}$ que está em questão não são as teorias científicas, mas sim o modo como no "nosso mundo" foram se delineando a natureza e a cultura como dois mundos apartados (LATOUR, 1994), ou seja, a natureza apenas como um objeto da ciência. De fato, o problema é que a ciência para grande parte da população continua sendo considerada como sinônimo de "certeza" e de "previsão". Segundo Mayer (1998, p. 221), "esta imagem da ciência está tão generalizada que contagia inclusive as reflexôes sobre o meio ambiente e os problemas ambientais".

A construção de uma educação divergente do modelo transmissivo de soluçóes e certezas de que fala Mayer (1998), nos parece dependente das possibilidades que construímos de conviver com a incerteza, a imprevisibilidade e a complexidade. No campo da educação científica, mas também no da 
educação ambiental, isso nos remete a um problema epistemológico já que o objeto mesmo das controvérsias científicas e socioambientais nos defronta com os limites das nossas formas de produção e reprodução do conhecimento. Assim, torna-se imprescindível reavaliar os modos de nos relacionarmos com esse saber, desenvolvendo nossa capacidade de fazer perguntas e de discutir as maneiras de se buscar as respostas. No entanto, se por um lado assumimos que a educação numa perspectiva socioambiental deve atuar na formação de espíritos críticos e questionadores, por outro reconhecemos que não existem caminhos seguros para o desenvolvimento de uma educação nesse sentido. Em outras palavras, "la seguridad se traslada desde la seguridad de los resultados a la seguridad sobre la validez y la significación de los procesos puestos en marcha" ${ }^{2}$ (MAYER, 1998, p. 224), modificando-se, dessa forma, a concepção construída a respeito da escola e da educação.

Ao se dar ênfase aos processos desloca-se o foco da prescrição e dos preceitos voltados aos resultados, para outro modo de se entender questôes como as de natureza socioambiental; outro modo que se nutre de experiências que, de alguma forma, subvertem formas tradicionais de conhecer. Um pouco disso que estamos tratando pode ser percebido no clássico relato de Flickinger (1994) a respeito de uma situação que se apresentou inusitada a um grupo de pesquisadores da sua universidade. Ao chegarem a uma pequena regiâo próxima a uma cidade alemá, que enfrentava desde o início dos anos de 1980 uma série de problemas ambientais de contaminação da água e do solo e para os quais nâo encontravam explicaçóes, os pesquisadores lançaram mão de uma abordagem considerada pouco usual.

Fazia-se necessário buscar um outro caminho, talvez complementar, para poder compreender os fatos. Por isto, em vez de recorrer aos instrumentos tradicionais da pesquisa analítico-experimental, os cientistas decidiram escolher um procedimento pouco comum, ou seja, uma "metodologia" à primeira vista irracional se comparada às regras do jogo científico: eles começaram a frequentar os lugares sociais da população imiscuindo-se, gradativamente, nas preocupaçóes, histórias e temores das geraçóes quanto ao futuro da regiáo [...]. (FLICKINGER, 1994, p. 199). 
A atitude de buscar caminhos diferentes dos usuais para se compreender situações e objetos que não se conhece de fato, poderia também implicar revirar aspectos com os quais não estamos habituados a lidar nas nossas práticas de pesquisa e de educaçáo, o que, nos termos do autor citado, nos forçaria a "sair do conhecimento racional-objetificador, no sentido de encontrar seu avesso complementar" (FLICKINGER, 1994, p. 202).

Com efeito, pode-se aceitar e reforçar a estrutura binária que se tornou "normal" entre natureza e cultura, fato e política, ciência e sociedade, ou, ao contrário, tratar do tecido que interliga as naturezas e as culturas. No entanto, apesar de nos defrontarmos diariamente com "objetos híbridos" - nem puramente objetos de ciência, nem puramente objetos de política (LATOUR, 1994, 2004) - nossos arcabouços de conhecimento, sobretudo aqueles que constituem o meio escolar, não sustentam possibilidades concretas de se lidar com essas redes de relaçôes sem recorrer a reducionismos. De fato, a cultura na qual estamos imersos sempre nos ensinou a separar os conhecimentos exatos do exercício do poder, assim como a natureza da cultura. Dessa forma, optar por um modo de compreender o nosso mundo a partir de novas "lentes", de uma perspectiva que considere a complexidade dos fenômenos e suas inter-relaçóes, exigiria tanto uma visão crítica dos nossos "modelos" epistemológicos, metodológicos, investigativos e didáticos, quanto à possibilidade de se tomar caminhos que apontem, inclusive, para a construção de novas subjetividades e intersubjetividades.

É nessa perspectiva que as questóes socioambientais não apenas se apresentam como uma possibilidade de educação transversal e interdisciplinar - já que se abrem ao conjunto das disciplinas escolares e das suas diferentes possibilidades de colaboração, associação e fusão - mas, também, supóem lidar com aspectos referentes a conhecimentos e valores, assim como a sensaçóes, percepçóes e interpretaçóes. Requer, portanto, assumir a responsabilidade pelo modo como somos capazes de compreender, conhecer e definir o mundo.

Nesse sentido, considerando-se a problemática socioambiental, ao mesmo tempo, uma oportunidade e também um desafio que nos coloca diante da necessidade de revisar nossas práticas, escopos e instrumentos utilizados no campo da educação, entrevemos como promissor um "paradigma indiciário", que atenda aquilo que pensamos ser um objetivo fundamental da educação científica e ambiental: aguçar o olhar e os sentidos para compreender o que se nos apresenta de modo complexo e não completamente visível. Uma perspectiva que releva os casos concretos, as pistas deixadas pelo caminho e a incerteza dos resultados. 


\title{
Fundamentação teórica: elementos de um paradigma indiciário
}

\author{
Nesse tipo de conhecimento entram em jogo \\ (diz-se normalmente) elementos imponderáveis: \\ faro, golpe de vista, intuição. (GINZBURG, \\ 1989, p. 179).
}

Dado o caráter complexo e múltiplo das questóes ambientais, Mayer (1998) já havia indicado a fertilidade de uma abordagem indiciária que, diversamente do modelo epistemológico das ciências naturais, se constituiria num modo de pensar e de proceder num mundo de diferenças e mudanças, onde construir histórias, ao mesmo tempo, internamente coerentes e adequadas aos indícios que se tem à disposição, poderia trazer à luz significados que, de outro modo, permaneceriam ocultos.

Carlo Ginzburg (1989) mostra como, no final do século XIX emerge, silenciosamente, no âmbito das ciências humanas um modelo epistemológico embasado no pressuposto de que para se compreender e interpretar um fato ou fenômeno seria necessário recorrer às diferenças, aos pequenos indícios, às pistas infinitesimais que, à primeira vista, permaneciam veladas. $\mathrm{O}$ historiador italiano recorda que, entre 1874 e 1876, aparece na Europa, notadamente na Alemanha, uma série de artigos sobre pintura italiana de um estudioso de arte chamado Giovanni Morelli, propondo um novo método para a atribuição (autoral) aos quadros antigos, o que suscitou entre os historiadores de arte da época reaçóes contrastantes e vivas discussóes. E não sem razão: atribuir autoria às obras não era uma tarefa fácil e os museus, dizia Morelli, estavam cheios de quadros atribuídos de maneira incorreta. Distinguir os originais das cópias era indispensável. Para tanto, propunha um método completamente novo: ao invés de se basear em características mais vistosas, como era usual, como "os olhos erguidos para o céu dos personagens de Perugino, o sorriso dos de Leonardo, e assim por diante", seria necessário "examinar os pormenores mais negligenciáveis, e menos influenciados pelas características da escola a que o pintor pertencia: os lóbulos das orelhas, as unhas, as formas dos dedos das mãos e dos pés" (GINZBURG, 1989, p. 144). Com esse método foram propostas dezenas e dezenas de novas atribuiçóes em alguns dos principais museus da Europa. 
A esse método surgiram críticas, mas também posiçōes interessadas. Comparava-se, por exemplo, o método de Morelli ao que era atribuído, quase nos mesmos anos, a Sherlock Holmes, por Arthur Conan Doyle, seu criador. "O conhecedor de arte é comparável ao detetive que descobre o autor do crime [do quadro] baseado em indícios imperceptíveis para a maioria" (GINZBURG, 1989, p. 145). Também havia quem intuísse paralelismo entre o método de Morelli e os trabalhos de Freud. Ginzburg (1989) faz notar que algumas dessas percepções atraíam a atenção para uma passagem do famoso ensaio de Freud "O Moisés de Michelangelo" (1914). Neste ensaio, o médico austríaco afirma que muito antes que pudesse ouvir e falar de psicanálise tomou conhecimento de certo especialista de arte cujos primeiros artigos haviam provocado uma revoluçáo nas galerias de arte da Europa ao propor um método que distinguisse entre as imitaçôes e os originais. Freud reconheceria que aquele método estaria estreitamente ligado à técnica da psicanálise médica: "Esta também tem por hábito penetrar em coisas concretas e ocultas através de elementos pouco notados ou despercebidos, dos detritos ou 'refugos' da nossa observação [...]" (FREUD, 1914 apud Ginzburg, 1989, p. 147). A respeito da influência do trabalho de Morelli para a cristalização da psicanálise, Ginzburg (1989, p. 149-50) ressalta que o que importava para Freud era a proposta de um método interpretativo centrado sobre resíduos e dados marginais, considerados reveladores "porque constituíam os momentos em que o controle do artista, ligado à tradição cultural, distendia-se para dar lugar a traços puramente individuais [...]". A individualidade artística, assim, identificada com os elementos subtraídos ao controle da consciência, revelavase naquilo que tinha de mais insignificante.

Entrevê-se nessa analogia entre os modelos de Morelli-Holmes-Freud o modelo da semiótica médica, o que náo é casual: Freud era médico; Morelli formou-se em medicina; Conan Doyle (o criador da dupla Holmes e Watson) havia, por sua vez, sido médico. Esse singular nexo entre os procedimentos de Morelli, Holmes e Freud, contribuiu para que se afirmasse, no final do século XIX - mais precisamente na década de 1870-1980, nas ciências humanas, um "paradigma indiciário”. Mas suas raízes, diz Ginzburg (1989), eram bem mais antigas.

Segundo o autor, esse paradigma indiciário, revelado nas chamadas ciências humanas, tem suas origens remotas na cultura do homem primitivo. Por milênios o homem foi caçador e nas suas inúmeras perseguiçóes aprendeu a "ler" as pistas deixadas pelas presas, suas pegadas, as marcas deixadas pelo 
caminho como ramos quebrados, estercos, pêlos, plumas, odores. Dessa forma, o paradigma indiciário remete a um saber ancestral de tipo venatório, já que lida com a capacidade de, a partir de dados aparentemente negligenciáveis, remontar a uma realidade complexa não experimentável diretamente. A isso se pode acrescentar que esses "dados" são sempre dispostos pelo observador de modo tal a compor uma sequência narrativa. Por isso completa: "o caçador teria sido o primeiro a 'narrar uma história' porque era o único capaz de ler, nas pistas mudas (se não imperceptíveis) deixadas pela presa, uma série coerente de eventos" (GINZBURG, 1989, p. 152).

"Decifrar" ou "ler" pistas também remete ao longo processo histórico que levou à invenção da escrita. Ginzburg (1989) mostra, também, como o saber venatório pode se conectar ao paradigma implícito nos textos divinatórios mesopotâmicos redigidos a partir do terceiro milênio a.C. (historicamente a escrita nasce nesse povo). Segundo ele, ambos referem-se ao minucioso reconhecimento de uma realidade não dada diretamente a conhecer. "De um lado esterco, pegadas, pêlos, plumas; de outro, entranhas de animais, gotas de óleo na água, astros, movimentos involuntários do corpo e assim por diante" (GINZBURG, 1989, p. 153). Mas, se por um lado podemos perceber que a adivinhação se voltava ao futuro e a decifração para o passado, por outro, "a atitude cognoscitiva era, nos dois casos, muito parecida; as operaçóes intelectuais - análises, comparaçóes, classificações -, formalmente idênticas" (GINZBURG, 1989, p. 153). É claro que apenas formalmente, visto que os contextos eram completamente diferentes. Essa atitude orientada para a análise de casos individuais, possíveis de serem reconstruídos através de pistas, sintomas, indícios, também ligava a arte divinatória ao direito, sendo que os próprios textos de jurisprudência mesopotâmicos não consistiam em coletâneas de leis ou ordenaçóes, mas na discussão de casos concretos.

Com todas essas ligações, Ginzburg (1989) procura mostrar como apareceu historicamente uma constelação de disciplinas centradas na decifração de signos de vários tipos, que se estendem dos "sintomas à escrita". Nessa virada, um papel de primeiro plano foi desempenhado por um paradigma definível como semiótico ou indiciário - o que é particularmente evidente no caso da medicina de Hipócrates que definiu seus métodos refletindo sobre a noção decisiva de sintoma (semeion). Nesse paradigma, a realidade não é transparente. O saber conjectural operava, de fato, em esferas das atividades humanas muito diferentes. "Mas esse paradigma permaneceu, como se disse, 
implícito - esmagado pelo prestigioso (e socialmente mais elevado) modelo de conhecimento elaborado por Platáo" (GINZBURG, 1989, p. 155).

Apesar da distância temporal a que se referem esses paradigmas, o autor sugere que já no século $\mathrm{V}$ a.C. começara a manifestar a polêmica, destinada a persistir até os dias de hoje, contra a incerteza da medicina. Desde o tempo de Hipócrates que as relaçôes entre o médico e o paciente se caracterizam pelo fato do segundo náo poder controlar o saber e o poder detidos pelo primeiro. $\hat{E}$ claro, durante os últimos 2.500 anos mudaram os termos da polêmica, ao lado das profundas transformações ocorridas nas noçôes de "rigor" e de "ciência", sobretudo em razão do surgimento de um paradigma científico, centrado na física de Galileu, mas que se revelou muito mais duradouro do que ela.

De fato, a ciência de Galileu tinha uma natureza totalmente diversa: o emprego da matemática e do método experimental implicava, respectivamente, a quantificação e repetibilidade dos fenômenos. De outra parte, a perspectiva individualizante excluía por definição a repetibilidade e admitia a quantificação apenas em funçóes auxiliares. Isso explica por que certos saberes, como a história, por exemplo, não tenha conseguido se tornar uma "ciência galileana": "[...] como o do médico, o conhecimento histórico é indireto, indiciário, conjetural" (GINZBURG, 1989, p. 157).

$\mathrm{Na}$ verdade, grande parte do conhecimento moderno ocidental constituiuse através de uma drástica seleção de elementos considerados "pertinentes", o que conduziu a sua contínua depuração de todas as referências sensíveis. Esse foi o caso da noção de escrita e de texto, desenvolvida durante o século XIX, em um sentido rigorosamente científico. Acontece o mesmo com a moderna ciência da natureza. A tradicional comparação medieval entre mundo e livro, fundada na evidência, na legibilidade imediata de ambos, é contrariada pelos postulados de Galileu, segundo os quais não se pode entender o mundo se não se aprende sua língua matemática, geométrica. Ou seja, tanto a natureza, como o texto, são entendidos como entidades a serem reconstruídas para além dos dados sensíveis.

Abre-se, então, um fosso entre o olhar científico fundado no chamado paradigma galileano e aquele que conhece a partir do individual. "Quanto mais os traços individuais eram considerados pertinentes, tanto mais se esvaía a possibilidade de um conhecimento científico rigoroso", diz Ginzburg (1989, p. 163). Negligenciar os traços individuais não garantiria por si só a aplicabilidade dos métodos físico-matemáticos (próprios do paradigma galileano) - mas, 
pelo menos, excluiria essa possibilidade de vez. Restava, então, ou sacrificar o individual em favor da generalização, ou elaborar um paradigma diferente fundado no individual, com toda uma cientificidade ainda por se definir.

Se a realidade é opaca, nos coloca Ginzburg (1989) que existem zonas privilegiadas - sinais, indícios - que permitem decifrá-la. Para tanto, é necessário não apenas averiguar nossos pressupostos de conhecimento, como dar lugar à intuição, a qual não se confunde com os vários irracionalismos difundidos nos séculos XIX e XX. O paradigma indiciário não tem nada de irracional, pelo contrário, constitui um modo racional de conhecimento difundido no mundo todo e cujas raízes remontam às culturas dos caçadores e camponeses e a uma medicina baseada nos sinais e nos sintomas aparentemente invisíveis ao olhar leigo. Trata-se de um paradigma que busca por diferenças e por aquilo que existe de singular. Exemplo disso nos oferece Duby (1999, p. 13) ao fazer um paralelo entre a Idade Média e a aurora do Terceiro Milênio, mostrando que "não são as semelhanças que vão nos impressionar, são as variaçốes que nos levam a fazer-nos perguntas".

Quando olhamos para o passado conseguimos juntar peças, pistas, sinais e recompor aquilo que tem sido a nossa história. $\mathrm{E}$ as histórias que se tornam possíveis de serem reconstruídas são totalmente únicas, casuais, não repetíveis e, portanto, não trazem à luz regularidades nem elementos que permitam sua generalização. Segundo Mayer (1998), as histórias permitem construir contextos e significados que de outro modo ficariam ocultos e, ademais, permitem explorar diversos caminhos de interpretação, já que funcionam com um conceito de racionalidade muito mais flexível.

Nessa perspectiva, entende-se que a compreensão das questôes socioambientais está mais próxima desse tipo de racionalidade do que do paradigma galileano. Trata-se de um campo de fenômenos, problemas e situaçōes aberto a interpretaçóes de diversas ordens, cujas histórias podem conectar, numa mesma narrativa, elementos sociais, culturais, políticos, econômicos, simbólicos e materiais.

\section{O paradigma indiciário como uma via para se refletir sobre os casos controversos}

Há tempos os casos são utilizados em escolas de Direito, Administração e Medicina para promover o ensino de princípios e práticas profissionais. No 
campo da formação de professores, mais recentemente, os casos também têm sido considerados estratégias pertinentes para a aprendizagem profissional da docência. Nesta última abordagem, o caso auxilia na educação, pois combina experiência e reflexão, assim como teoria e prática. De fato, um caso é sempre uma história de algo e nesse sentido pode ser visto como um exemplo de uma classe de eventos ou uma instância de uma categoria mais ampla, carreando princípios teóricos e práticos que, pela narrativa, frequentemente, emergem e se tornam explícitos (SHULMAN, 1992).

Conhecer um caso, nessa perspectiva, é ter conhecimento de eventos específicos, cujos contextos e elementos estão bem definidos. Em geral, um caso é uma história, situada no tempo e no espaço. Segundo Herreid (1996, 1997), essas histórias trazem uma problemática ou controvérsia de importância para uma dada sociedade. Para este autor, a estrutura da controvérsia tanto está presente na formação dos profissionais do Direito, como pode ser transformada em instrumento pedagógico para ser utilizado na escola.

$\mathrm{Na}$ educação científica os casos que envolvem controvérsias sociocientíficas e socioambientais também têm sido utilizados como estratégias de ensino por apresentarem a possibilidade de promover além da aprendizagem dos processos da ciência e dos conhecimentos científicos e tecnológicos, os contextos e implicações das relações entre ciência, tecnologia, sociedade e ambiente. Nesses contextos, os métodos de casos parecem ser pertinentes porque possibilitam promover maior articulação entre os mundos natural e o campo social. Assim, acredita-se poder transcender à tradicional perspectiva dos conteúdos das ciências naturais para englobar aspectos éticos, socioeconômicos, políticos e culturais, até entâo próprios de abordagens das ciências humanas.

Contudo, o que nos parece ainda mais relevante para ser aqui destacado é a possibilidade de se favorecer, por meio da utilização de casos dessa natureza no processo educativo, o exercício de uma postura investigativa que, sobretudo, vai de encontro a uma abordagem de resolução de problemas que privilegia o conhecimento essencialmente instrumental e técnico-científico, em detrimento do caráter filosófico, histórico-social e epistemológico das questóes ambientais. Mas porque os casos controversos podem carregar essa potencialidade de desenvolver uma abordagem diferenciada para se pensar e analisar questóes socioambientais?

Para além do que muito já se falou e vem sendo falado acerca dos casos controversos, em termos de suas múltiplas dimensóes e de sua natureza 
complexa, acreditamos que o estudo desses casos pode subverter a maneira pela qual vem se enfrentando questóes que não podem ser reduzidas a situações ideais. Se uma das características fundamentais das ciências naturais, particularmente no que se refere aos procedimentos utilizados na produção de conhecimento, é justamente a idealização dos fenômenos e a generalização de suas causas, as questôes socioambientais, por sua vez, requerem outra abordagem, já que sua compreensão e análise carecem de que se considerem todas suas particularidades, bem como as imbricações entre elas. Noutras palavras, o estudo dos casos contribui para que na escola o estudo do particular também seja valorizado como forma de alcançar conhecimento.

Se tivermos como uma das metas da contemporaneidade a formação de sujeitos proativos para o enfrentamento de situaçóes-problema, é fundamental que se ensine não apenas os procedimentos das ciências naturais, mas também procedimentos que venham a contribuir para transformaçóes mais profundas na cultura. Desse modo, os casos controversos adquirem relevância nos campos da educação científica e da educação ambiental, sobretudo porque, a nosso ver, podem ensinar as pessoas a refletirem com base em indícios que, embora não evidentes, contribuem para que se atribua outros sentidos ao problema socioambiental, além daqueles que são mais evidentes nos discursos técnicocientíficos.

O fato de esses casos carregarem em si mesmos o potencial da controvérsia possibilita aos sujeitos perceberem para além de suas múltiplas dimensões e complexidades, isto é, de perceberem que o enfrentamento de problemas, sobretudo os socioambientais, requer um tratamento diferenciado, uma "prática indiciária", que sem dúvida exigirá do sujeito um compromisso epistemológico e ético e um grande esforço para ponderar e articular os diferentes indícios que pode vir a encontrar no estudo do caso.

Casos exemplares que geraram conflitos socioambientais, a exemplo dos que ocorreram na construção das barragens de Alqueva na regiāo do Alentejo, Portugal (BAROLLI; FARIAS; LEVI, 2006), de Três Irmãos no Estado de São Paulo, Brasil (FARIAS; CARVALHO, 2007), entre outros, já foram utilizados em situações de ensino como problemas abertos que visavam contribuir para que as pessoas pudessem exercer suas capacidades de formar opinióes informadas e desenvolver o pensamento crítico e a independência intelectual.

O que nos interessa aqui, no entanto, não é discutir ou analisar os resultados dessas experiências didáticas, embora ambas tenham alcançado 
resultados interessantes e promissores, na medida em que possibilitaram aos estudantes que participaram das experiências perceber a necessidade de considerar a diversidade de posicionamentos e de conhecimentos para avaliação dos casos. Nossa intenção é de aprofundar uma reflexão sobre casos dessa natureza e tecer argumentos para sua utilização na educação científica e ambiental numa perspectiva indiciária.

$\mathrm{Na}$ composição de casos controversos são apresentadas, de modo geral, informaçóes, consideraçóes e argumentaçóes acerca de diferentes perspectivas sobre um conflito socioambiental e suas múltiplas dimensões - social, cultural, econômica, política, científica, jurídica, ética etc. O que queremos destacar aqui é que essas diversas dimensões dizem respeito a disciplinas que em sua maioria são eminentemente qualitativas, isto é, que fazem parte do que denominamos ciências humanas. Desse modo, a análise desses casos pede uma abordagem diferente daquela epistemologicamente apoiada no paradigma galileano que requer a quantificação e a repetibilidade dos fenômenos. De fato, os casos são únicos, até porque os contextos históricos, geográficos, sociais, culturais etc, acabam por definir desdobramentos singulares.

Os impactos socioambientais causados pela construção de uma barragem, por exemplo, produzem muitos efeitos que, em determinados aspectos, são semelhantes independentemente das localidades em que as usinas hidrelétricas se instalam. Porém, é a singularidade daqueles contextos que melhor caracterizam a repercussão desses impactos e, portanto, cada um desses casos. Assim, nos parece que a análise dessas situações irá exigir uma abordagem cujo eixo epistemológico está, sobretudo, assentado na compreensão do individual e menos numa abordagem que pretenda alcançar a generalizaçáo. Certamente, a opção por esse tipo de abordagem nos coloca em contato com o fato de que náo podemos prever com grande margem de segurança os efeitos de determinada intervenção no ambiente, mesmo que ela já tenha ocorrido em diversas situaçóes. Ou seja, há um indeterminismo intrínseco e uma margem de incerteza num processo de construçâo de conhecimento sustentado por um paradigma indiciário.

Ressalta-se que essas características das disciplinas indiciárias indeterminismo e incerteza - estiveram presentes durante toda história da humanidade, tendo se expressado fortemente na medicina, como nos ensina Ginzburg (1989, p. 166) ao comentar o texto A certeza da medicina, de Cabanis, publicado no final do século XVIII: 
As razôes da "incerteza" da medicina pareciam ser fundamentalmente duas. Em primeiro lugar, não bastava catalogar todas as doenças até compô-las num quadro ordenado: em cada indivíduo, a doença assumia características diferentes. Em segundo lugar, o conhecimento das doenças permanecia indireto, indiciário: o corpo vivo era por definição inatingível. Certamente podia-se seccionar o cadáver; mas como, do cadáver já corrompido pelos processos da morte chegar às características do indivíduo vivo? Diante dessa dupla dificuldade, era inevitável reconhecer que a própria eficácia dos procedimentos da medicina era indemonstrável. Em conclusão, a impossibilidade de a medicina alcançar o rigor próprio das ciências da natureza derivada da impossibilidade da quantificação, a não ser funçôes puramente auxiliares; a impossibilidade da qualificação derivada da presença ineliminável do quantitativo, do individual; e a presença do individual, do fato de que o olho humano é mais sensível às diferenças (talvez marginais) entre os seres humanos do que entre as diferenças entre as pedras ou as folhas. Nas discussôes sobre a "incerteza” da medicina, já estavam formulados os futuros nós epistemológicos das ciências humanas.

Assim, a incerteza de que nos fala Ginzburg, não se coloca como algo a ser definitivamente eliminado ou mesmo abominado, já que de alguma forma ela é intrínseca à natureza de um conhecimento construído com base num paradigma diferente do galileano, fundado num conhecimento do individual. É interessante pensarmos, inclusive, como a medicina atual tem se esforçado para se afastar de um conhecimento indiciário, ao procurar se apoiar na realizaçáo de infindáveis exames de laboratório e, portanto, num processo de quantificação de diferentes indicadores, para diminuir cada vez mais a margem de incerteza de seus diagnósticos, encontrar padróes de sintomas para as doenças e, até mesmo, garantir aos médicos salvaguarda de possíveis falhas de diagnósticos. Raros são os médicos, sobretudo os alopatas, que exercitam seu saber indiciário, que conjecturam sobre as doenças, perscrutando os sintomas de cada paciente na perspectiva de conhecer e compreender os indícios que caracterizam as diferentes formas individualizadas pelas quais se manifestam. Talvez fosse mais 
promissor, no caso da medicina, mas não só dela, não abandonar o paradigma indiciário, mas procurar juntá-lo ao generalizante.

Essa postura investigativa indiciária, a nosso ver, configura-se como abordagem importante e necessária para análise de casos controversos, que também comportam incerteza, imprevisibilidade e não se submetem ao saber generalizante. Ademais, pode permitir não apenas a elaboraçáo de conhecimentos que requerem uma compreensão sistêmica da realidade, capaz de apreender a dinâmica global de um sistema a partir do estudo das redes singulares de relaçóes que o configuram, mas porque pode nos levar a mudar a maneira pela qual nos percebemos em relação às questóes socioambientais. Assim, a multiplicidade de dimensóes que configuram os casos controversos, ganha importância na medida em que oferece uma infinidade de dados ou pistas, que irão mediar a interação entre sujeito e objeto. É essa interação que irá permitir a compreensão do caso e, desse modo, da produção de sentidos.

No âmbito de nossas reflexóes o termo compreensão pode ser entendido em correspondência a um preceito spinozista que Bourdieu (2003) se apropria na obra Miséria do Mundo, para fazer dele um pressuposto do pesquisador de natureza social: compreender, explica Bourdieu, é tomar as pessoas e os acontecimentos como são, apreendendo-os como necessários, relacionando-os metodicamente às causas e às razóes que fazem como são. Ou seja, para que se possa avaliar a situaçáo exposta pelo caso, de modo a poder se surpreender com os sentidos que podem ser produzidos a partir dele, nos parece necessário percorrer uma etapa na qual o sujeito procura compreender. Essa talvez seja a aprendizagem de maior relevância que podemos adquirir por meio dos estudos de casos. Isto é, para além do que tem sido amplamente destacado nos campos da educação científica e ambiental, de que os casos controversos contribuem para formar opiniōes informadas, acreditamos que a principal contribuição que os estudos de casos podem oferecer é a de desenvolver uma perspectiva investigativa de caráter indiciário no sentido que Ginzburg atribui a esse termo. Em outras palavras, os casos nos parecem estratégias didáticas interessantes, principalmente por criarem condiçóes para que se construa e se exercite um saber do tipo indiciário, isto é, um saber caracterizado pela capacidade de, a partir de dados aparentemente negligenciáveis, remontar a uma realidade não experimentável.

Essa postura intelectual, para o pesquisador, assemelha-se àquela requerida na compreensão e interpretação de um texto. Nesse processo o leitor não pode 
simplesmente impor ao texto convicçóes, opiniōes ou perguntas motivadas por experiências estranhas a ele, já que é o texto que lhe fala e interroga. Não há um possível sentido autêntico-original do texto, seu sentido se constitui ao longo de um jogo de perguntas e respostas, de um diálogo entre o intérprete e o texto que năo admite o domínio exclusivo, seja por parte do intérprete ou do próprio texto. É desse modo que o querer compreender o texto supera uma explicação causal e, ao mesmo tempo, exige que o intérprete se esclareça em relação a seus pré-conceitos originais.

Essa abordagem que se vale de um saber indiciário, quando utilizada na análise de casos controversos, pode permitir ao sujeito que busca compreender o conflito socioambiental de se colocar no contexto mais amplo do conflito instaurado, ao perceber-se como parte da história do íntimo envolvimento entre o homem e o ambiente em seu sentido pleno. Ou seja, nesse plano metodológico, compreender um caso controverso, irá requerer a disponibilidade de nos colocarmos como parte da rede de relaçôes que compóem o conflito, isto é, de reconhecermos na história do ambiente, nossa própria história.

Essa implicação do sujeito nos problemas socioambientais nos parece ser talvez a única possibilidade de superação, pelo menos em boa parte, de muitas crenças construídas ao longo da história da humanidade e, ao mesmo tempo, de poder assumir de maneira consciente a participação no planejamento de nosso futuro. Nesse ponto é que, a partir dos elementos do presente, o saber indiciário nos remete tanto ao passado quanto ao futuro. Esse pode ser um caminho promissor para que os sujeitos passem a considerar sob outra perspectiva suas escolhas e decisóes quanto o seu agir em relação ao ambiente. Esta consideração que, como afirma Flickinger (1994, p. 204), "deveria levar em conta, por exemplo, os fatores ambientais já antes da decisão quanto à ação, em vez de seguir apenas uma estratégia 'end of pipe'”. Esse tipo de estratégia está, inclusive, bastante difundido na atualidade, basta analisarmos a situação em que nos encontramos quanto aos produtos e materiais considerados recicláveis. Raramente se observa um esforço na recuperação de nossa história na perspectiva de explicitar o quanto estamos implicados na produção desses materiais e na responsabilidade em continuarmos consumindo produtos e artefatos recicláveis. Em contrapartida, a reciclagem aparece, muitas vezes, como a solução para o problema do lixo, colocando a ciência e a tecnologia como verdadeiras tábuas de salvação no enfrentamento do acúmulo de materiais recicláveis. 


\section{Considerações finais}

Há muitos aspectos e relaçóes que podem ser inferidos com base numa abordagem de casos controversos que não se restringe ao modelo de explicação causal, mas que explora um saber indiciário. De fato, assim que conhecemos o caso e os diversos argumentos que caracterizam a controvérsia, uma tendência que logo se manifesta é a de ponderar as diferentes opinióes apresentadas e, ao mesmo tempo, emitir um julgamento pautado em prós e contras e em nossas convicçóes e valores. Ao fazermos esse percurso corremos o risco de tomar as questóes controversas socioambientais apenas em sua fase final, isto é, como fato já consumado e nấo como processo construído ao longo do tempo, o que nos permitiria explorar os condicionantes que fazem com que se apresentem naquela forma final.

Nos dias de hoje, nota-se que o modo pelo qual os indivíduos percebem e compreendem o mundo é conduzido, sobremaneira, por um caráter individualista, de aniquilamento do diferente, de desprezo pelas minorias e de apego a banalidades construídas histórica e culturalmente pelas relações humanas. As formas de pensamento hegemônicas se constituíram sob a dicotomia entre homem e natureza, pressupondo a dominação do primeiro sobre a segunda. Certamente a maneira pela qual os casos controversos são abordados pode ser facilmente atravessada por essa visão, já que uma de suas decorrências é atribuir às questôes socioambientais, causas externas ao sujeito, que via de regra constitui-se em uma entidade genérica ou generalizável. Porém, para que seja explorada a potencialidade, no sentido de subverter esse modo de entendimento dos casos controversos, nos parece particularmente promissor abordá-los por meio de uma postura indiciária, buscando articular os indícios que nos oferecem as diversas relaçóes que dão contorno à controvérsia ou ao conflito socioambiental, buscando problematizar os fazeres da ciência e da tecnologia e suas implicaçóes na sociedade e nos indivíduos.

Para além de conhecer os argumentos contra e a favor do empreendimento, que poderiam até sustentar uma possível tomada de posiçáo, um saber indiciário poderia evidenciar aquilo que não está absolutamente explícito nos argumentos técnico-científicos: o caráter social da ciência e os modos por meio dos quais esses conhecimentos podem vir a se articular a determinados interesses de grupos sociais, de acordo com os diferentes contextos que lhes dizem respeito. Além disso, esse saber pode evidenciar que existem controvérsias mesmo entre 
membros da comunidade científica e que o conhecimento científico não fixa a "verdade" e nem é "incontestável". Essa é uma interpretação que para ser alcançada requer daquele que estuda o caso, uma postura investigativa, uma metodologia em que o sujeito ao procurar compreender o fato socioambiental, o faz percorrendo um processo de interpretação em que mantêm em suspenso suas crenças e valores, bem como suas próprias convicções. Quando nossas representações dominam exclusivamente nossas interpretaçôes, somos levados inevitavelmente a abordar o caso por meio do modelo de explicaçáo causal dos fatos e a nos distanciarmos de nosso saber indiciário.

O fazer da ciência na sociedade não pode ser facilmente dedutível dos manuais. No entanto, a análise de casos controversos, com base num saber indiciário, mostra-se bastante favorável para que se possa inferir, entre outros aspectos, o caráter conflituoso da ciência, ou mesmo da tecnologia no progresso social.

Além disso, como mencionado, a composição de casos traz implícitos elementos que, se devidamente explorados, podem ainda desembocar na problematização de uma das dimensóes do conceito de cidadania, e o que é a cidadania ambiental.

A compreensão dos casos controversos, por meio de uma abordagem investigativa fundamentada em um paradigma indiciário, parece-nos essencial não só porque se propóe a conjecturar e a decifrar os elementos que compóem a complexidade de um caso socioambiental, mas, sobretudo, porque pode contribuir para que os sujeitos se impliquem com a produção do caso, interpretando-o como um acontecimento, isto é, como algo que irrompe não como fato consumado, mas como uma marca na história do pensamento que configura um dado contexto cultural (FARIAS, 2011).

Ao contrário de se conceber ou mesmo justificar um caso socioambiental apenas como uma consequência secundária das relaçóes sociais e econômicas, uma postura investigativa com base em um saber indiciário problematiza as origens do caso, podendo contribuir para que o sujeito perceba o entrelaçamento que existe entre sua própria história e o acontecimento. Isso nos remete, ainda, ao fato de que na relação com o mundo, o sujeito se constitui como tal em um campo em que é convocado a pensar no âmbito do já pensado e a assumir sua responsabilidade na construção de relaçóes éticas. 


\title{
Notas
}

\begin{abstract}
${ }^{1}$ A escola busca, em geral, apresentar soluçôes, em lugar dos problemas que lhes correspondem - as leis "naturais", as fórmulas para realizar cálculos, a "correta" interpretação histórica, os significados "apropriados" dos textos literários. A escola "transmissiva" requer certezas que justifiquem seu papel: o saber deve ser certo, universal, objetivo. No entanto, mesmo a escola "construtivista", que atualmente representa a alternativa mais avançada, declara, por um lado, que os estudantes devem construir o próprio saber, mas não se oferece como exemplo de construção crítica desse saber, ou mesmo considera esses saberes por meio de um enfoque plural das disciplinas. Nesse sentido, seu objetivo parece ser o de reconstruir as mesmas certezas (da escola de antes), e dificilmente aceita que se construam saberes e epistemologias diferentes daqueles já estabelecidos. (MAYER, 1998, p. 222, tradução nossa).

2 "a segurança se transfere desde aquela referente aos resultados até à segurança sobre a validade e o significado dos processos em andamento" (MAYER, 1998, p. 224, tradução nossa).
\end{abstract}

\section{REFERÊNCIAS}

AIKENHEAD, Glen S. STS science in Canada: from policy to student evaluation. In: KUMAR, David; CHUBIN, Daryl (Ed.). Science, technology \& society: a source book on research and practice. New York: Kluwer Academic; Plenum Publishers, 2000. p. 49-89.

AMORIM, Antonio Carlos Rodrigues. O que foge do olhar das reformas curriculares: nas aulas de Biologia, o professor como escritor das relaçóes entre ciência, tecnologia e sociedade. Ciência \& Educação, Bauru, SP, v. 7, n. 1, p. 47-65, 2001.

AULER, Décio; BAZZO, Walter Antonio. Reflexões para a implementaçâo do movimento CTS no contexto educacional brasileiro. Ciência \& Educação, Bauru, SP, v. 7, n. 1, p. 1-13, 2001. 
BAROLLI, Elisabeth; FARIAS, Carmen R. O.; LEVI, Elifas. O potencial de assuntos controversos para a educação em uma perspectiva CTS. In: ENCONTRO PERSPECTIVAS DO ENSINO DE BIOLOGIA, 10., 2006, São Paulo. Anais... São Paulo: FEUSP, 2006.

BOURDIEU, Pierre (Org.). A miséria do mundo. Petrópolis, RJ: Vozes, 2003.

CACHAPUZ, Antonio (Org.). Perspectivas de Ensino. Porto: Centro de Estudos de Educação em Ciência, 2000. (Formação de Professores Ciências, v. 1).

CARVALHO, Luiz Marcelo de. Que educação ambiental desejamos? Ciência em Foco, Campinas, SP, v. 1, n. 3, p. 1-22, 2010.

CEREZO, José Antonio López. Los estúdios de ciencia, tecnologia y sociedad. Revista Iberoamericana de Educação, Madrid, n. 20, p. 217-225, mayo/ago. 1999.

COSENZA, Angélica; MARTINS, Isabel. Contribuiçôes da abordagem CTS para a educação ambiental: os "lugares" do ambiente na produção científica sobre CTS. In: ENCONTRO PESQUISA EM EDUCAÇÃO AMBIENTAL, 6., 2006, Ribeirão Preto. Anais... Ribeirão Preto, SP: UNESP, 2011.

DUBY, Georges (Org.). Ano 1000, ano 2000: na pista dos nossos medos. São Paulo: Editora UNESP, 1999.

FARIAS, Carmen R. O. A problemática ambiental na perspectiva do acontecimento. In: REUNIÃO ANUAL DA ANPEd, 34., 2011, Natal. Anais... Natal: ANPEd, 2011. Disponível em: <http://34reuniao.anped. org.br/images/trabalhos/GT22/GT22-1086\%20int.pdf $>$. Acesso em: 21/04/2014.

FARIAS, Carmen Roselaine Oliveira; CARVALHO, Washington Luiz Pacheco. Desvelando relaçóes Ciência-Tecnologia-Sociedade-Ambiente a partir de um processo judicial sobre danos ambientais. Revista Eletrônica do Mestrado em Educação Ambiental, Rio Grande, RS, v. 17, p. 316-330, jul./ dez. 2006. 
FARIAS, Carmen Roselaine Oliveira; CARVALHO, Washington Luiz Pacheco. O direito ambiental na sala de aula: significados de uma prática educativa no ensino médio. Ciência \& Educação, Bauru, SP, v. 13, n. 2, p. 157-174, ago. 2007.

FARIAS, Carmen Roselaine Oliveira; FREITAS, Denise de. Educação Ambiental e relaçóes CTS: uma perspectiva integradora. Ciência \& Ensino, Piracicaba, SP, v. 1, n. especial, p. 1-13, nov. 2007.

FLICKINGER, Hans-Georg. O ambiente epistemológico da educação ambiental. Educação e Realidade, Porto Alegre, RS, v. 19, n. 2, p. 197-207, jul./dez. 1994.

GAUDIANO, Edgard Gonzalez. Educação Ambiental. Lisboa: Instituto Piaget, 2005.

GINZBURG, Carlo. Mitos, emblemas, sinais: morfologia e história. São Paulo: Companhia das Letras, 1989.

GRÜN, Mauro. Em busca da dimensão ética da educação ambiental. Campinas, SP: Papirus, 2007.

GUIMARÁES, Mauro. Caminhos da Educação Ambiental: da forma à ação. 5. ed. Campinas: Papirus, 2011.

HERREID, Clyde Freeman. Structured controversy: a case study strategy - DNA fingerprinting in the Courts. Journal of College Science Teaching, Arlington, v. 26, n. 2, p. 95-101, nov. 1996.

HERREID, Clyde Freeman. What is a case? Journal of College Science Teaching. Arlington, p. 92-94, 1997.

LATOUR, Bruno. Jamais fomos modernos: ensaio de antropologia simétrica. Bauru, SP: EDUSC, 1994.

LATOUR, Bruno. Politicas da natureza: como fazer ciência na democracia. Bauru, SP: EDUSC, 2004.

LAYRARGUES, Philippe Pomier. Identidades da Educação Ambiental Brasileira. Brasília, DF: MEC, 2004. 
LOUREIRO, Carlos Frederico B.; LIMA, Jacqueline Girão Soares.

Educação ambiental e educação científica na perspectiva Ciência, Tecnologia e Sociedade (CTS): pilares para uma educação crítica. Acta Scientiae, ano 11, n. 1 , p. 88-100, jan. 2009.

MAYER, Michaela. Educación ambiental: de la acción a la investigación. Enseñanza de las Ciencias, v. 16, n. 2, p. 217-231, 1998.

PAYNE, Phillip. Embodiment and Action Competence. In: JENSEN, Bjarne; SCHNACK, Karsten; SIMOVSKA, Venka (Ed.). Critical environmental and health education: research issues and challenges. Copenhagen: The Danish University of Education, 2000. p. 185-208.

POZO, Juan Ignacio; CRESPO, Miguel Ángel Gómez. A aprendizagem e o ensino de ciências: do conhecimento cotidiano ao conhecimento científico. Porto Alegre: Artmed, 2009.

REIS, Pedro. O ensino da ética nas aulas de ciências através do estudo de casos. Interacçôes, Lisboa, n. 5, p. 36-45, 2007.

SANTOS, Maria Eduarda Vaz Moniz. Que educação? Para que cidadania? Em que escola? Lisboa: Santos-Edu, 2005. 2v.

SAUVÉ, Lucie. Uma cartografia das correntes em educação ambiental. In: SATO, Michèle; CARVALHO, Isabel Cristina M. (Org.). Educação Ambiental: pesquisa e desafios. Porto Alegre: Artmed, 2005. p. 17-45.

SILVA, Luciano Fernandes; CARVALHO, Luiz Marcelo. A temática ambiental e o processo educativo: o ensino de física a partir de temas controversos. Ciência \& Ensino, Piracicaba, SP, v. 1, n. especial, p. 1-12, nov. 2007.

SHULMAN, Lee S. Toward a pedagogy of cases. In: SHULMAN, Judith H. (Org.) Case methods in teacher education. New York: Columbia University, 1992. p. 1-29. 


\section{Controversial cases under the focus of an evidential paradigm: science teaching in the formative horizon of environmental citizenship}

\section{Abstract}

In this work, a critical to the epistemological and pedagogical dominant models in the area of science teaching and they present an educational perspective of the use of controversial cases in science teaching, will be presented, taking into account the formative requirements of environmental citizenship. The central argument is that these cases may contribute to the understanding of environmental questions in the school from an investigative attitude which has its roots in an epistemological model of the human science, that might be designated by "an evidential paradigm". For this reason, this study seeks to problematize our ways to produce school knowledge in the science area and it also aims to offer a theoretical and methodological basis to be used in the controversial cases in the school education, highlighting its contributions to the environmental education. It is concluded sustaining that, in addition to knowing the technical-scientific arguments about environmental controversies, a teaching methodology based in disagreement cases would contribute to reveal what is not absolutely explicit on those arguments: the social and political
Cas controversés du point de vue d'un paradigme probante: I'enseignement des sciences dans l'horizon de la formation de la citoyenneté environnementale

\section{Résumén}

Cet article présentera une critique aux modèles pédagogiques et épistémologiques dominantes dans l'enseignement des sciences et un point de vue sur l'utilisation des cas controversés qui prend en compte les attentes de l'éducation pour la citoyenneté environnementale. L'argument central est que les cas peuvent contribuer à la compréhension des questions environnementales à l'école à partir d'une démarche d'investigation qui a ses racines dans un modèle épistémologique des sciences humaines, qui peut être appelé paradigme "probante». Pour cela, nous cherchons à problématiser nos modes de production des connaissances scolaires dans le domaine des sciences et d'offrir une approche théorique et méthodologique à l'utilisation des cas controversés dansl'enseignement scolaire, soulignant sa contribution à l'éducation environnementale. L'article conclut en affirmant que, en plus de connaitre des arguments techniques et scientifiques sur les controverses environnementales, une méthode d'enseignement basée sur les cas controversé aiderai à découvrir ce qui n'est pas tout à fait explicite dans ces arguments, comme la nature 
character of science and technology and also our involvement in History and in environment as moral subjects.

Keywords: Science teaching. Enviromental education. Controversial cases. sociale et politique de la science et de la technologie et notre implication dans l'histoire et l'environnement comme sujets moraux.

Mots-clés: L’enseignement des sciences. L'éducation environnementale. Cas controversés.

\section{Carmen Roselaine de Oliveira Farias}

E-mail: crofarias@gmail.com

Elisabeth Barolli

E-mail: bethbarolli@gmail.com

Recebido em: 19/5/2013

Versão final recebida em: $12 / 8 / 2013$

Aprovado em: 17/8/2013 